\title{
Near Field Communication in Tourism a Conceptual Paper
}

\author{
Roman Egger*
}

\begin{abstract}
Modern society is virtually inconceivable without mobile devices and the consequent use of mobile services. The multitude of technologies incorporated in the tiniest of space has turned mobile phones, and smart phones in particular, into the Swiss knives of our times. What is currently perceived to be one of the most promising technologies for the future is Near Field Communication (NFC), which will most likely become the standard in mobile devices in the years to come. Due to the novel nature of this technology, the assessment of its importance for the tourism industry is still relatively unclear. The author is one of the first to focus on NFC in tourism, with the aim of introducing NFC technology and drafting first responses to the following questions: What benefit can NFC technology have for tourism and what functionalities can it trigger? What are the possible future applications in tourism and what challenges will tourism be faced with in this respect?
\end{abstract}

Keywords: NFC, Near Field Communication, RFID, Mobile, mTourism

\section{Introduction}

Information and communication technologies (ICT) have been playing an important role in tourism and have been changing it continuously for some twenty years now. The restructuring triggered by ICT has always led to a modification of strategies and adaptation of business practices, providing the tourism industry with its highly dynamic character. (Buhalis, Law 2008) Since the beginning of the new millennium, the Internet in particular has brought about a revolution in global interaction for a rapidly growing group of users. The new information, communication and distribution opportunities that opened up at the same time, have entailed a wealth of new tools and solutions now being used by the tourism industry.

Mobile telephony developed parallel to ICT and by no means less quickly. In 1992, the first GSM-enabled mobile phone was introduced and the number of users started to grow continuously. As from the year 2000, the number of people using mobile phones increased enormously, leading to a rapid development of the devices based on the more and more exacting demands placed on performance. When the iPhone was introduced

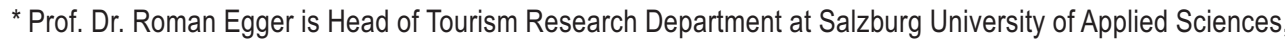
Austria. Email: roman.egger@fh-salzburg.ac.at
} 
in 2007, starting the spiral for the most successful smart phones, the mobile Internet breakthrough had arrived. While a few years ago the attempt to bring the Internet to the - at that time under-developed - mobile phone by means of WAP technology had failed, mobile Internet use has meanwhile become a matter of course, not least thanks to the continuously changing data tariffs of mobile network operators. Powerful operating systems, such as iOS5 and Android, integrated photo and video cameras, position and acceleration sensors, transmission technologies such as

Bluetooth and WLAN, GPS for geo positioning and much more are standard features of modern smart phones. In combination with access to the Internet - via mobile website or applications (apps) - myriads of new situations of usage are created. A new technology that will most probably be used in mobile phones and also offering various possible applications for the tourism industry is wireless connectivity Near Field Communication technology. NFC promises to make payment per mobile phone possible in future, to replace keys and open doors, to revolutionise ticketing for events and in the transportation sector, to exchange data between mobile phones, retrieve information from tags and smart posters and much more.

A look at the scientific exploration of the "mobile services \& tourism" issue shows that only relatively few papers have been published on this topic so far. The contributions have mainly been made by the IFITT community that has clearly committed itself to this issue with the ENTER conference and the Journal of Information Technology \& Tourism. In 2010, Egger and Jooss published a German anthology entitled "mTourism - mobile Dienste im Tourismus" in German; no corresponding work has been published so far in the English literature. A search for publications on Near Field Communication in tourism provides just a mere hand full of papers (mainly Chung \& Tsai 2012; Borrego-Jaraba et al. 2011; Isaksson 2010; Baldo 2010; Öztaysi et al 2009; Hardy et al 2008; Madlmayr \& Scharinger; Haid 2007 as well as Hui Eow 2009). These papers deal only superficially with NCF, treat it as a side subject or describe a very concrete application from a mostly technology-oriented perspective.

This paper tries to close this gap in the literature by analysing NFC technology in the context of tourism and trying to draft possible applications. The attempt is made to present a technology that could become omnipresent in tourism routines in the near future.

\section{Mobile Services in Tourism}

It is impossible to imagine our lives without mobile phones. This is not only true for Western, industrialised societies but is a global phenomenon, with striking rates of use reported mainly from the Asian and African regions. (Egger, Jooss 2010 S12) According to the World Travel Market Trends Report 2011, Africa has even taken over the lead in the mCommerce sector, with the travel industry at the forefront of the movement (WTM 2011 online). Mobile technologies are going to revolutionise tourism (Egger, Buhalis 2008) and mobile services are already being used in numerous sectors of the tourism industry (Ferry et al. 2010). The key features accounting for the breakthrough of mobile solutions are, above all, the possibilities of localisation and personalisation. In future, the demands will be on a pro-active design of corresponding products and on a responsive 
approach to the needs and requirements of holiday-makers in all the phases of their holidaying. Whether on the journey to the point of destination or on site: scarcely anyone will want to do without the convenience of being contactable everywhere and at all times, and everybody will want to be able to obtain place-related information. The transmission technology as such is not so important to the user; it is rather the convenience and usability, i.e. the intuitive operation of the device, as well as fast and secure access to information and communication that count. Convincing and relevant content in the right context of use is seen as the most important acceptance criterion. The ITB World Travel Trends Report 2010/2011 states that already more than 40 percent of tourists worldwide are owners of smart phones with Internet access (IPK 2011, 19); and with the wealth of forecasts at hand, there is consensus in at least one respect: The convergence of Internet and mobile telephony will lead to ubiquitous supply of information, not least for people who are away from their home base on vacation.

\section{NFC Technology}

\subsection{The technology behind NFC}

Mobile interaction with the environment is ensured by transmission technologies such as infrared, Bluetooth, WLAN or visual 2D codes. Contactless interface technologies such as NFC (Near Field Communication) and RFID (Radio Frequency Identification) are on the advance, however (Aust 2005). NFC is a transmission technology based on the standard of contactless smart cards, or more concrete ISO/IEC 14443. With a transmission distance of approx. $10 \mathrm{~cm}$, NFC has deliberately been developed for the close proximity or contact range. Similar to MiFare systems and RFID, NFC is also based on the concept of electromagnetic induction that makes fast, safe and user friendly exchange of data based on the touching paradigm (Borrego-Jaraba 2011) between sender and target possible (Wiedmann et al 2009; SITA 2012; Madlmayr, Scharinger 2009). In contrast to RFID, two generally equal devices are used (an initiator and a target) that can work in both operating modes - which is also what accounts for the performance. The two-way communication allows for three modes of application: NFC devices build up a bi-directional data connection (peer-to-peer) or one NFC device is used to read or write an external tag (reader/writer mode) or the NFC device is used as a smart card (card emulation mode) (Madlmayr, Scharinger 2009).

Figure I: NFC application modes
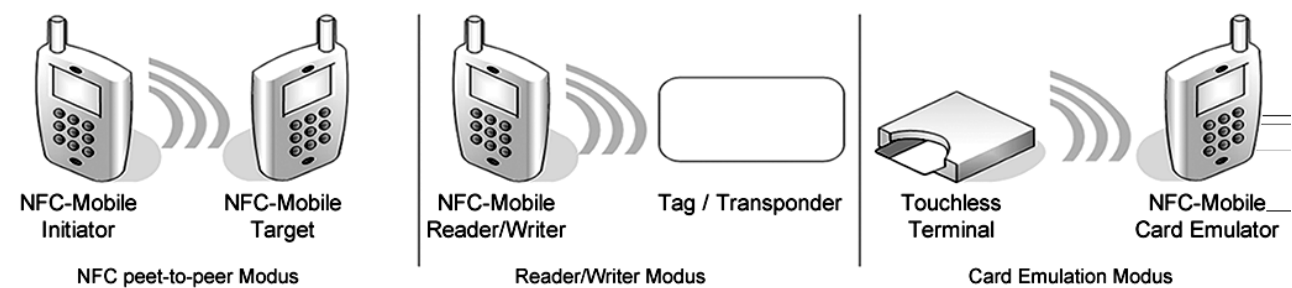

Source: adapted and modified from Madlmayr, Scharinger 2010 
The advantages of the NFC technology are manifold. With NFC, users of mobile phones can safely exchange data and information with other NFC-enabled end points and corresponding tags. There is no need for complicated pairing, as in the case of Bluetooth. Due to the immediate proximity, there is no misunderstanding as to the devices between which communication is to be established. NFC can also be ideally connected with other protocols such as WLAN, UMTS or Bluetooth. Another essential benefit of NFC is that the devices can be operated passively, i.e. without power.

The table below gives an overview of the most important functionalities and possible applications of NFC and NFC trials in the tourism context.

Table I: NFC functionalities \& possible applications

\begin{tabular}{|c|c|c|}
\hline Functionality & Possible application & Trial in tourism context \\
\hline Mobile payment & $\begin{array}{l}\text { The mobile phone is used as a credit } \\
\text { or debit card at the point of sale. }\end{array}$ & $\begin{array}{l}\text { Google Wallet (e.g. New } \\
\text { Jersey Transit System), } \\
\text { NFC payment for London } \\
\text { Olympic Games } 2012 \text { (by } \\
\text { Visa \& Samsung) }\end{array}$ \\
\hline \begin{tabular}{|l|} 
Information supply \\
\end{tabular} & $\begin{array}{l}\text { You tap your phone on a tag that is } \\
\text { incorporated in objects (e.g. cards or } \\
\text { smart posters) or fixed to the surface } \\
\text { and you receive access to the } \\
\text { respective additional information. }\end{array}$ & $\begin{array}{l}\text { Museum of London, } \\
\text { Frankfurt Transport } \\
\text { Systems, World Expo } 2012 \\
\text { in Yeosu, Korea }\end{array}$ \\
\hline Access authorisation & $\begin{array}{l}\text { The telephone is turned into a virtual } \\
\text { key. With the respective authorisation, } \\
\text { hotel room doors can be opened, or } \\
\text { access to mountain lifts or skiing } \\
\text { resorts, etc. is granted. }\end{array}$ & $\begin{array}{l}\text { Clarion Hotel in } \\
\text { Stockholm, Nordic Choice } \\
\text { Hotels, SAS, }\end{array}$ \\
\hline Network access & $\begin{array}{l}\text { Log onto a Wi-Fi network or get } \\
\text { Bluetooth by tapping your phone to a tag }\end{array}$ & $\begin{array}{l}\text { Can be created with apps } \\
\text { such as "WifiTap". }\end{array}$ \\
\hline $\begin{array}{l}\text { Management of loyalty, } \\
\text { bonus \& membership } \\
\text { cards }\end{array}$ & $\begin{array}{l}\text { Loyalty, bonus or membership cards } \\
\text { are stored on the mobile phone and } \\
\text { can be managed there. }\end{array}$ & \\
\hline Mobile ticketing & $\begin{array}{l}\text { Customers pay with their mobile } \\
\text { phone and receive a virtual boarding } \\
\text { pass for a public transport system, } \\
\text { such as the London Underground for } \\
\text { example. }\end{array}$ & $\begin{array}{l}\text { EAT restaurant chain; Pass } \\
\text { and Fly by Air France, } \\
\text { Nice Côte d'Azur Airport } \\
\text { and Amadeus }\end{array}$ \\
\hline $\begin{array}{l}\text { Workforce } \\
\text { management }\end{array}$ & $\begin{array}{l}\text { Workforce can register by touching } \\
\text { the tag on a backend system, for } \\
\text { example, and will then receive further } \\
\text { instructions. }\end{array}$ & $\begin{array}{l}\text { Transport for London } \\
\text { (TfL), City of Barcelona, } \\
\text { Deutsche Bahn }\end{array}$ \\
\hline
\end{tabular}




\begin{tabular}{|l|l|l|}
\multicolumn{1}{|c|}{ Functionality } & \multicolumn{1}{c|}{ Possible application } & \multicolumn{1}{c|}{ Trial in tourism context } \\
\hline Identification & $\begin{array}{l}\text { The mobile phone as an identification } \\
\text { object to acknowledge certain actions. } \\
\text { To identify the driver of a rental car, } \\
\text { for example, to open the door and start } \\
\text { the engine by means of keyless go. }\end{array}$ & $\begin{array}{l}\text { Hertz Car Rental } \\
\text { Modern and Contemporary } \\
\text { Art Museum of Nice }\end{array}$ \\
\hline Location based services & $\begin{array}{l}\text { The use of NFC for location-based } \\
\text { services. Especially in buildings to be } \\
\text { preferred over GPS; navigation and } \\
\text { application concepts for museums and } \\
\text { indoor events, for example. }\end{array}$ & \\
\hline
\end{tabular}

\subsection{Penetration and acceptance of NFC}

After mobile voice and text and mobile Internet communication, NFC (Near Field Communication) is often referred to as the third wave in the mobile telephony revolution (IATA 2009). At the World Mobile Congress 2012 in Barcelona, the most important annual event of mobile communication, NFC was the core innovation presented this year, besides the LT (Long Term Evolution) transmission technology. The Gartner Hype Cycle 2011, a benchmark often used to assess technologies, also ranks NFC payment at the peak of inflated expectations. The Gartner Hype Cycle can, however, only be seen as a vague indicator of the current expectations on NFC as it does not refer to general NFC developments but only to the payment functionality, i.e. only to one of the many possible applications.

A decisive criterion for the future success or failure of a new technology standard is the general consensus of business linked to the commitment to jointly support the new technology. In the case of Near Field Communication, this consensus and commitment are ensured by the NFC Forum founded in 2004. The task of the Forum is to advance the use of Near Field Communication technology by developing specifications, ensuring interoperability among devices and services, and educating the market about NFC technology (NFC Forum 2012). The 160 members include manufacturers of mobile phones, network operators, service providers, application providers, financial service institutions and many more. The fact that heavy-weights such as Google (since 2011) are also onboard (Flores 2011) actively pushing this technology (e.g. Google Wallet, the NFC-enabled Google cell phone Samsung Nexus S) will most probably also have a positive effect on NFC penetration.

To date, the NFC chip is installed in only a dozen mobile phone models, but all the major mobile phone manufacturers have announced NFC-enabled phones for this year's Mobile World Congress. Gartner analysts predict an increase to nearly 100 million NFCenabled end points in the year 2012 (Thompson 2012). At the same time, the most powerful telcos (e.g. AT\&T, Vodafone, China Mobile and Deutsche Telecom) are also pushing NFC technology; in 2011 an agreement was reached that NFC-enabled SIM cards should become a worldwide standard (Walters 2011). This would guarantee the breakthrough 
in the penetration of NFC. Another possible option is refitting NFC technology with NFC-enabled micro SD cards (e.g. for the iPhone; there are heavy speculations about the NFC-ability of the iPhone5 at the moment) (Engadget 2012; Borrego-Jaraba 2011). But at first, smart stickers can be used to add simple NFC functionalities to mobile phones. Scandinavian Airlines (SAS), for example, gives out smart stickers to all EuroBonus Gold frequent fliers across Scandinavia to make check-in and boarding processes easier and more efficient. The stickers can be used at self service machines, security, fast track, lounges, tax free shopping and at the gate (Clark 2011).

The use of QR codes is often said to be an alternative to NFC. These 2D codes attached to physical objects can be scanned by means of a camera phone. A QR code reader processes the information stored in the code thereby linking physical objects with mobile services (Canadi et al. 2010). While QR codes are already used in tourism - for example on boarding passes - they still have some security drawbacks and in the long run they are unlikely to stand their ground to the superior NFC technology. Google picked up this trend and started to replace its QR code window decals of Google Places by NFC chips (Rosoff 2011).

\section{NFC in Tourism}

The tourism industry is a highly information-intensive business sector (Poon 1993) involving a wide variety of different processes. In organisations, ICT affect mainly the operative, structural and strategic levels, reducing communication and process costs while increasing flexibility, interactivity, efficiency, productivity and competitiveness (Buhalis and Egger 2005). As NFC is a transmission standard, it will be mainly processes that will be innovated by it. The following table provides an overview of the most important strategic and operative functionalities that can be expected for companies and the most essential benefits for tourists.

\section{Table II: Benefits and functionalities of NFC}

\section{Possible strategic effects for companies}

Heightening of organisational efficiency and effectiveness

Improvement of quality and services

Increase of competitiveness

Differentiation in product and market segments

Personalisation and mass customisation of services, linked to increase in value at all product levels

Reduction of costs and creation of competitive edge (monetary advantages)

Creation of competitive edge of temporary nature thanks to higher performance and efficiency

Restructuring of business processes and rationalization of operative tasks 


\begin{tabular}{|l|}
\hline Use of novel and innovative business practices \\
\hline Long-term competitive out performance \\
\hline Establishment of new, strategic partnerships \\
\hline Possible operative effects for companies \\
\hline Optimised distribution of information and optimised reservation processes \\
\hline Simplification of the relationships between service provider and customer \\
\hline Reservation, check-in, check-out, boarding \\
\hline Improvement of customer service \\
\hline Active management of visitor flows and optimised waiting time management \\
\hline Performance monitoring and installation of feedback mechanisms \\
\hline Linking of social media marketing activities \\
\hline Possible effects for tourists \\
\hline More convenient handling \\
\hline Faster process handling (e.g. check-in, boarding) \\
\hline Increased safety due to NFC specific specifications \\
\hline Perceived quality of service will be increased \\
\hline
\end{tabular}

Source: adapted and modified from Buhalis and Egger 2005

In the section above, the most important NFC functionalities that can be expected and some example applications and trials in the tourism context were presented. The focus below will be on some selected cases of use in various sectors of tourism.

\section{- Use case - The airline industry}

The airline industry is characterised by a high level of processes between passengers and the airport and/or airline, and the entire service chain offers scope for the use of NFC. The Corporate Air Travel Survey 2009 conducted by the International Air Transport Association (IATA) concluded that $50 \%$ of passengers worldwide would appreciate more self-service options to accelerate the travel processes. The "Fast Travel 2020 Vision" of IATA is consequently designed to offer self-service options to $80 \%$ of passengers worldwide. Accordingly, the IATA together with the GSM Association (GMSA) has defined several NFC use cases for airports that were tested in a project carried out jointly by SITA Lab and Orange Business Services with the aim of analyzing if NFC can remove the neuralgic points of mobile usage in air travel.

The possible scenarios of NFC use investigated in the field test ranged from passenger check-in and baggage check-in to security checkpoints, lounge access, board and post 
flight. In the check-in procedure, the NFC boarding pass can be transmitted to the passenger's mobile phone online, via a kiosk or through the air. A trusted service manager is used to do this. The boarding pass is then safely loaded into a travel wallet that is saved on the SIM card of the traveller. There are intentions to replace the currently used 2D barcodes by NFC in future, as the 2D codes meet with only little acceptance among travellers and because their security is vulnerable: they can be forwarded, duplicated and manipulated. If the forecasts about the distribution of NFC technology and NFC-enabled mobile devices come true, between $50 \%$ and $80 \%$ of all boarding passes issued worldwide could be transmitted to mobile phones according to SITA (2012) by 2018. The share of mobile boarding passes with 2D barcodes in 2011 was a mere $2 \%$.

The passenger at the security checkpoint would touch the NFC terminal with the mobile phone, the boarding pass is called up and the departure control system host lets the passenger pass. No data connection is needed, no special application needs to be started and the mobile phone does not even need to be switched on.

\section{- Use case - The hotel and catering industry}

The Clarion Hotel in Stockholm carried out a successful pilot test for checking in and out of hotels in cooperation with Assa Abloy in 2011, the biggest and leading manufacturer of lock systems. In the test scenario, guests booked their rooms as usual via one of the various channels. On the day of arrival they received a welcome text message. Via a link to a mobile website, they were able to download the virtual NFC key by indicating their room number. The mobile hotel key application developed by Assa Abloy saves the virtual key on the SIM card of the mobile phone. In the concrete test scenario, the testers were given a Samsung S5230 phone, as only a few mobile phones are equipped with an NFC chip and only this model can save keys and other secure applications to the SIM card. The guests can then go directly to their rooms and open the door by a simple move of their mobile phone. When they check out they tap their phone on an NFC tag in the lobby or check out manually. In both cases, the digital key is deactivated. Should a guest lose his or her mobile phone, the hotel can also remotely deactivate the key. In a next step of development, the digital key is to be provided with additional functionalities, such as payment and loyalty services (Balaban 2012).

Another possible use is for what are referred to as "smart posters". Smart posters have NFC tags incorporated in them where information such as URLs or defined apps, text messages, phone numbers and calling cards can be stored and called up. In the case of stored URLs, tourists tap on the respective chart or text of the smart poster backed-up by the tag. The respective URL is then called up in the browser of the smart phone. The illustration below shows a smart poster for the Grand Park Hotel in Bad Hofgastein in the province of Salzburg, Austria. This poster could be put up in the lobby, lift or hotel room. Guests can call up current weather forecasts, information about the lift operations in the skiing resorts, summit web cams and an interactive city map via the smart poster. It is also possible to book spa treatments, to check the dinner menu in the restaurant, to call up the event calendar, to provide feedback or visit the hotel's fan page on Facebook. 
Figure II : Smart poster of a hotel

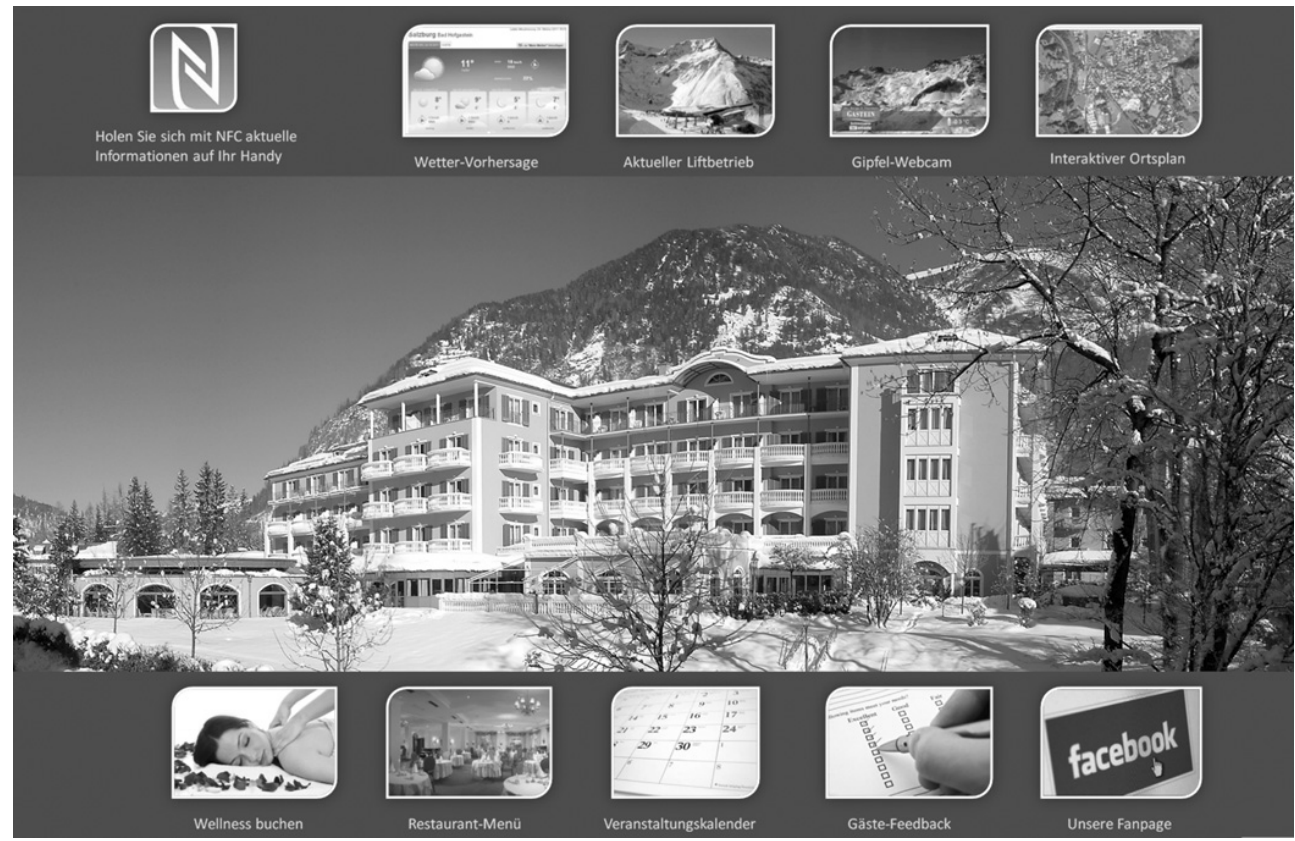

Source: The author

\section{- Use case - Destinations}

The use of NFC enabled Destination Cards in the destination context would appear to be an interesting and promising approach. Many destinations have implemented destination cards to increase guest loyalty, boost the image and brand of the destination and to ultimately improve turnover (Bruhn 2001). At the same time, the use of destination cards provides and generates key data about customer segments and the use of provisions in the region. In most cases, individual regional service provisions are bundled and offered as a package. In future, destination cards can be stored directly on the mobile phone of the guest. Access rights, payment functions and bonus systems and loyalty programmes could all be managed via the mobile destination card. Despite the fact that a wide, highly diversified, promising scenario of possible applications seems to be given, the author is not aware of any pilot tests in this sector.

At the destination level, not only the breakthrough of NFC technology as such, but also the combination with other transmission technologies will be of decisive importance. This for example, when it comes to removing barriers that currently exist with regard to the use of mobile services. Destinations, mainly cities but also skiing resorts, parks, etc. increasingly offer their Municipal Wireless Networks; and with free Internet access a major barrier for the use of data services is brought down. 


\section{Discussion and Conclusion}

NFC technology promises security, uncomplicated use and an added value that can be easily communicated to the user. And yet - as with every technology thrust - it remains to be seen if and to what extent consumers will embrace this technology. A wide range of possible applications opens up for the tourism industry, both in the $\mathrm{B} 2 \mathrm{C}$ and in the $\mathrm{B} 2 \mathrm{~B}$ area. The main challenge to be mastered will be the avoidance of insular solutions and the development of industry-wide standards instead; such as for check-in and boarding processes in the aviation industry. Manufacturers of mobile devices, mobile communication service providers, credit card companies, and so on are currently fervently promoting the introduction of NFC. If a far-reaching penetration is followed by acceptance on the part of the customer, the technology push could before long be turned into a technology pull effect. Customers would then soon demand solutions from the tourism industry that live up to their expectations. If this happens, there will be no way of avoiding NFC in future - not even for small and medium-sized companies.

\section{References}

Aust, Jessica (2005) Mobile Interaktion mit der realen Umwelt. In Mobile Interaktion and Mobile Media. LFE Medieninformatik. http://www.hcilab.org/events/ mobileinteraction/reports/04_MobileInteractionsWithTheRealWorld_JessicaAust.pdf; 23.12.2010

Balaban, Dan (2011) NFC Hotel Room Keys Could Unlock Other Services, Says Vendor.; 07.02.2012

Baldo, David; Benelli, Giuliano; Pozzebon, Alessandro (2010) The SIESTA project: Near Field Communication based applications for tourism. Accepted at CSNDSP 2010, The 7th International Symposium on Communication Systems, Networks \& Digital Signal Processing, Newcastle upon Tyne, United Kingdom, 21-23 July 2010

Borrego-Jaraba, Francisco; Ruiz, Irene; Gómez-Nieto, Miguel Ángel (2011) A NFCbased pervasive solution for city touristic surfing. In: Personal and Ubiquitous Computing. Vol. 15, Nr. 7; p 731-742.

Bruhn, Manfred (2001) Kundenkarte. Vahlens großes Marketinglesixon. Diller. Munich; p 862.

Buhalis, Dimitrios (2003) eTourism: Information technology for strategic tourism management. Pearson (Financial Times/Prentice-Hall)

Buhalis, Dimitrios and Egger, Roman (2005) Informations- und Kommunikationstechnologien als Mittel zur Prozess- und Produktinnovation für den Unternehmer. In: Peters, Mike and Pikkemaat, Birgit (Eds.) Innovationen im Tourismus. ESV-Verlag; Berlin; p 163-166.

Buhalis, Dimitios and Law, Rob (2008) Progress in information technology and tourism management: 20 years on and 10 years after the Internet - The state of eTourism research. Tourism Management 29; p 609-623.

Canadi, Michael; Höpken Wolfram; Fuchs, Matthias (2012) Application of QR Codes 
in Online Travel Distribution. In: Gretzel, Ulrike; Law, Rob; Fuchs, Matthias (Eds.) Information and Communication Technologies in Tourism. Springer; Vienna, New York; p 137-158.

Chung, Shang-Hsuan and Tsai, Chieh-Yuan (2012) In: Decision Support Systems, Vol. 52, Nr. 2; p 514-527.

Clark, Sarah (2011) SAS to introduce NFC to airports http://www.nfcworld.com/2011/ 06/15/38035/sas-to-introduce-nfc-to-airports/. 24.02.2012

Clark, Sarah (2012) Visa and Samsung to unveil Olympics NFC payments app at Mobile World Congress. . 24.02.2012

Coskun, Vedat; Ok, Kerem; Ozdenizci, Busra (2012) Near Field Communication (NFC) From Theory to Practice. John Wiley \& Sons.

Egger, Roman and Buahlis, Dimitrios (2008) Mobile Systems. In Egger, Roman and Buhalis, Dimitrios (Eds.) eTourism Casestudies. Butterworth Heinemann; p 417-425.

Egger, Roman and Jooss, Mario (2010) Die Zukunft im mTourism - Ausblicke auf Technologie- und Dienstentwicklung. In Egger, Roman and Jooss Mario [Ed] mTourism. Mobile Dienste im Tourismus. Gabler Verlag, Wiesbaden; p 12-25.

Engadget (2012) Moneto NFC microSD to bring contactless features to any Android phone. http://www.engadget.com/2012/01/11/moneto-nfc-microsd-contactless-paymentAndroid-iPhone/. 19.02.2012

Ferri, Fernando; Grifoni, Patrizia and Guzzo, Tiziana (2010) Social Aspects of Mobile Technologies on Web Tourism Trend. In. Unhelkar Buvhan (Ed.) Handbook of research in mobile business: technical, methodological, and social perspectives, Idea Group; p 292-303.

Flores, Marcel (2011) Google joins NFC Forum along with 31 other new members. http://www.intomobile.com/2011/03/31/google-joins-nfc-forum-along-31-other-newmembers/. 19.02.2012

Haid, Elisabeth (2007) RFID im Tourismus. Grundlagen, Einsatzgebiete, Umsetzung. Saarbrücken; VDM Verlag.

Hardy, Robert; Rukzio, Enrico; Wagner, Matthias and Paolucci, Massimo (2008) Touch \& Interact: Applied to a Tourist Guide Prototype. Demonstration at NFC Forum Global Competition at 2nd European NFC Developers Summit (WIMA 2008), Monaco.

Hui Eow, Amy Szw; Guo Jiayu; Guan Sheng-Uei (2009) Tourist applications made easier using Near Field Communications. In Pagani, Margariha (Ed.) Encyclopedia of Multimedia Technology and Networking, Second Edition; IGI Global; p 1399-1400.

IATA (2011) The benefits of Mobile NFC for Air Travel. http://www.iata.org/whatwedo/stb/fast-travel/Documents/iata-public-whitepaperissue1.pdf. 12.02.2012

IPK (2011) ITB World Travel Trends Report 2010/2011. http://www.hospitalitynet.org/ file/152004432.pdf. 02.01.2012

Isaksson, Stefan (2010) Possible Applications of RFID Technology in Tourism Services. In Börstler, Jürgen; Drewes, Frank; Gulliksson, Harkan (Eds.) USCCS. p 51-59. 
Madlmayr, Gerald and Scharinger, Josef (2010) Neue Dimensionen von mobile Tourismusanwendungen durch Near Field Communication Technologie. In: Egger, Roman and Jooss, Mario (Eds) mTourism - mobile Dienste im Tourismus. Gabler. Wiesbaden; $\mathrm{p}$ 75-88.

McLean, Heather (2011) Transport for London to accept NFC payments from 2012 http://www.nfcworld.com/2011/07/12/38537/transport-for-london-to-accept-nfcpayments-from-2012/. 14.01.2012

NFC-Forum (2012) NFC-Forum: About the Forum. http://www.nfc-forum.org/aboutus/. 06.02.2012.

Öztaysi, Basar; Baysan, Serdar; Akpinar, Fatma (2009) Radio frequency identification (RFID) in hospitality. In: Technovation, 29; p 618-624.

Poon, Aurelia (1993) Tourism, technology and competitive strategies. Oxford: CAB International.

Rosoff, Matt (2011) Google kills off those little square codes you can with your phone. http://articles.businessinsider.com/2011-03-31/tech/29979593_1_qr-codes-androidnfc-forum. 08.01.2012

SITA (2012) Near Field Communications Demo. http://www.sita.aero/content/near-fieldcommunications-demo. 12.02.2012

Tagawa, Koishi (2011) Why NFC is bigger than paying with your mobile Phone. Presentation at 4G World NFC Summit. http://www.nfc-forum.org/resources /presentations/koichi_tagawa_keynote_4g_world_final.pdf. 16.01.2012

Thompson, Cadie (2012) Nier field communication the next mobile boost? http://www.cnbc.com/id/45766855/Near_Field_Communication_the_Next_Mobile Boost. 16.01.2012

Walters, Ray (2011) NFC-enabled SIM cards to become a worldwide standard. http://www.extremetech.com/mobile/105683-nfc-enabled-sim-cards-to-become-aworldwide-standard; 02.02.2012

Wiedmann, Klaus-Peter; Reeh, Marc-Oliver; Schumacher, Henrik (2009) Employment and Acceptance of Near Field Communicaiton in Mobile Marketing WTM (2011) African Travel Industry Leads the World in Mobile Commerce. . 05.01.2012 